\author{
Blaise Julien Meyrat \\ Stéphan Tercier \\ Nicolas Lutz \\ Bénédict Rilliet \\ Margarita Forcada-Guex \\ Olivier Vernet
}

\section{Introduction of a urodynamic score to detect pre- and postoperative neurological deficits in children with a primary tethered cord}

Received: 2 July 2003

Published online: 14 October 2003

(C) Springer-Verlag 2003

\author{
B. J. Meyrat $(\bowtie) \cdot S$. Tercier · N. Lutz \\ Department of Pediatric Surgery, \\ Centre Hospitalier Universitaire Vaudois \\ (CHUV), \\ 1011 Lausanne, Switzerland \\ e-mail: \\ blaise-julien.meyrat@chuv.hospvd.ch \\ Tel.: +41-21-3143075 \\ Fax: +41-21-3143076 \\ B. Rilliet · O. Vernet \\ Department of Neurosurgery, \\ Centre Hospitalier Universitaire Vaudois \\ (CHUV), \\ 1011 Lausanne, Switzerland \\ M. Forcada-Guex \\ Division of Neonatology, \\ Department of Pediatrics, \\ Centre Hospitalier Universitaire Vaudois \\ (CHUV), \\ 1011 Lausanne, Switzerland
}

\author{
Abstract Object: An increasing \\ number of asymptomatic children are \\ diagnosed with occult spinal dysra- \\ phism, raising the question of their \\ optimal management. Urodynamic \\ study (UDS) is the most reliable \\ method of detecting neuro-urological \\ abnormalities in these children. The \\ rate of postoperative retethering \\ ranges from 10 to $20 \%$ and is not \\ always immediately clinically signif- \\ icant. The aim of this prospective \\ study was to develop a reliable \\ method that could be used in the \\ preoperative assessment and postop- \\ erative follow-up of children with a \\ tethered cord syndrome (TCS). \\ Methods: From 1989 to 1997,15 \\ children underwent spinal cord un- \\ tethering for TCS. Preoperatively, \\ patients were assessed with MRI and \\ UDS. Postoperative UDS were re- \\ peated at 6- to 12-month intervals.
}

Four UDS parameters were identified, graded, and added to obtain a UDS score. A group of 38 children without dysraphic condition was used as control and allowed the calculation of a normal score. Conclusions: There was a statistically significant difference in the preoperative UDS scores between the control group and the study group $(p<0.001)$. Postoperatively, there was a statistically significant improvement $(p<0.001)$ in UDS scores. UDS score is a reliable tool for identifying and quantifying neuro-urological disorders in patients with TCS. Postoperatively, this score was useful in the early diagnosis of spinal cord retethering.

Keywords Tethered cord · Children . Urodynamics $\cdot$ Score $\cdot$ Spinal dysraphism $\cdot$ Spina bifida

\section{Introduction}

Tethered cord syndrome (TCS), first described by Garceau in 1953, is characterized by the low fixation of the spinal cord, with a conus situated below the intervertebral space L1-L2 [8]. Fixation may be caused by an intradural lipoma, a thickened filum, a spinal cord tumor, diastematomyelia, or a dermal sinus, producing traction on the spinal cord. Stretching of the caudal end of the spinal cord may alter the mitochondrial oxidative metabolism, causing progressive neurological, urological, and/ or orthopedic deficits [24, 28].

With the advent of magnetic resonance imaging (MRI), an increasing number of children are diagnosed with occult spinal dysraphisms, raising the question of their optimal management when clinically asymptomatic. For a long time, it has been widely accepted that patients suffering from TCS may deteriorate if spinal cord untethering is not performed promptly $[10,15,21]$. Nonetheless, the optimal time to perform surgery remains controversial. Although the majority of authors consider that spinal cord untethering improves or merely stabilizes neuro-urological status, some studies have demonstrated postoperative neurological deterioration [13, 22]. In cases of lipoma of the conus, surgery carries significant risks and its long-term efficacy has even been questioned. In a recent large series of children with lumbosacral lipomas, failure to prevent the onset of neurological deficits 
following spinal cord untethering and lipoma debulking was reported in almost half of the patients [22]. This led the authors to no longer advocate prophylactic surgery for lipomas of the conus. Instead, they limit surgical indication to patients with neuro-urological and/or orthopedic deficits, and to those with abnormal urodynamic studies (UDS).

In primary TCS, neurological deficits may appear late in the course of the disease. Furthermore, medical history and neurological examination in younger children are often difficult and non-specific. If neuro-urological disorders are not apprehended early enough, treatment may be unduly delayed. This situation has encouraged the quest for an objective, reliable, and reproducible tool that would permit early detection of neuro-urological disorders at any age, and could also be used in the follow-up of patients operated upon for TCS, since the rate of spinal cord retethering ranges from 10 to $20 \%[4,13]$.

Although MRI allows the diagnosis of TCS, it has limitations for postoperative follow-up and early detection of refixation. MRI is nonspecific in differentiating postsurgical fibrosis from neural structures [20]. Alternative MRI techniques have been used showing no advantage for the evaluation of spinal cord retethering [14, 27]. Neither is ultrasound of any use for this indication [5]. Somesthetic-evoked potentials are an invasive and poorly tolerated method with no proven value in predicting neurological deterioration [23].

At present, UDS is the most reliable method of detecting neuro-urological disorders associated with TCS, and of recognizing early postoperative neurological deterioration $[15,26]$. This technique may be used regardless of the child's age [9].

Several parameters are used in the evaluation of UDS. Analysis of bladder volume, compliance, and detrusor activity allows the evaluation of the filling phase. Analysis of vesico-sphincteric synergy is used to assess the voiding phase. Up to now, these parameters have generally been studied separately [7, 13, 25]. Like others, we believe that multiple parameter evaluation is more reliable [7]. Therefore, we graded each of these four parameters and summed them to obtain a total UDS score that provided a global dynamic assessment of the patient's evolution.

We report our results and experience with this urodynamic score in the diagnosis and long-term follow-up of 15 children operated upon for a primary tethered cord.

\section{Materials and methods}

Study group

Between 1989 and 1997, 15 children (10 boys and 5 girls) with primary TCS, aged 5 months to 15 years (mean \pm SD: $5 \pm 4$ years), underwent spinal cord untethering in our institution. Preoperative radiological imaging included conventional spine $\mathrm{X}$-rays in 12 patients, voiding cysto-urethrogram (VCUG) in 10, and spinal MRI in all. UDS were routinely performed in all patients preoperatively. All investigations were carried out by the same team, without sedation or anesthesia, according to the following standardized method. Micro-tip transducers were used for pressure measurements. These were 6-8 F one-lumen catheters with two transducers placed at a distance of $3-4 \mathrm{~cm}$ from one another. The first transducer was placed in the bladder, the second at the level of the internal urethral sphincter. A reference transducer catheter was placed in the rectum in order to monitor the intra-abdominal pressure. Assessment of the activity of the external urethral sphincter was made by recording the EMG activity of the external anal sphincter with perineal surface electrodes. As recommended by some authors [11], the rate of liquid instillation during the filling of bladder never exceeded one-twentieth of the total bladder capacity per minute. Depending on the age of the patient, the investigation was performed with the child sitting or recumbent.

The four parameters used for UDS evaluation were:

1. Bladder volume

2. Compliance

3. Detrusor activity

4. Vesico-sphincteric synergy during micturition

Each parameter was graded according to the importance of deviation from normal values.

Bladder volume was measured when the child started to urinate or showed discomfort. In patients with abolished repletion sensation, volume was determined when intravesical pressure reached $30 \mathrm{~cm} \mathrm{H}_{2} \mathrm{O}$ [12]. Values were then expressed as a percentage of normal values for age, which were calculated using the formula: $\mathrm{y}=30+30 \mathrm{x}$, where $y$ is the volume in milliliters and $x$ the age in years [19]. Bladder volume was graded from 0 to 5 . On this scale, 0 represented a normal bladder volume and 5 a bladder volume of $<20 \%$ of the normal value (Table 1 ).

Compliance was measured by dividing the increment of bladder volume by the concomitant increment of intravesical pressure $(\Delta \mathrm{V} /$ $\Delta \mathrm{P}$ ) during the filling phase II, as recommended by the International Children's Continence Society (ICCS) [19]. Compliance was graded from 0 to 4 . A normal compliance $\left(\geq 25 \mathrm{ml} / \mathrm{cm} \mathrm{H}_{2} \mathrm{O}\right)$ was attributed a grade 0 , whereas a compliance below $10 \mathrm{ml} / \mathrm{cm} \mathrm{H}_{2} \mathrm{O}$ was assigned the poorest grade 4 (Table 1).

Detrusor activity was analyzed during the filling phase in order to detect uninhibited contractions or systoles. Bladder contraction was defined as an increase of more than $2 \mathrm{~cm} \mathrm{H}_{2} \mathrm{O}$ above the resting bladder pressure, whereas an increase of $\geq 15 \mathrm{~cm} \mathrm{H}_{2} \mathrm{O}$ was considered as a systole [19]. The presence of isolated contractions does not always imply a neurological disorder, especially in toddlers. The exact time of appearance and their frequency during the filling phase are more important factors than their presence or absence alone [2]. Detrusor activity was graded from 0 to 5 . On this scale, 0 represented a normal detrusor activity without any uninhibited contraction or systole, grade 1 described the occurrence of frequent bladder contractions during the whole filling phase, and grades increased with both the occurrence of contractions and systoles and their frequency. Grade 5 was attributed to hyperkinetic bladders exhibiting frequent systoles during the entire filling phase and to flaccid bladders without any contraction during micturition (Table 1).

Vesico-sphincteric synergy reflects the integrity of the parasympathetic sacral arch and pathways between the pons and the micturition center at the sacral level. Vesico-sphincteric dyssynergy has been classified into three types [3]. We evaluated this parameter similarly and graded it from 0 to 3 . Synergic sphincter was graded 0 . Grade 1 represented the absence of relaxation with a sudden increase in EMG activity, concomitant with the beginning of 
Table 1 Grading of urodynamic studies (UDS) parameters. $C V$ calculated volume

\begin{tabular}{lllll}
\hline Grade & Parameter & & \\
\cline { 2 - 5 } & Bladder volume $(\% \text { of } C V \text { norm })^{\mathrm{a}}$ & Compliance $(\Delta \mathrm{V} / \Delta \mathrm{P})$ & Detrusor activity & Vesico-sphincteric synergy \\
\hline 0 & $\geq 100$ & $\geq 25$ & Normal & Synergy \\
1 & $80-99$ & $20-24$ & Frequent contractions in all phases & Lack of relaxation \\
2 & $60-79$ & $15-19$ & Systoles end phase II & Intermittent dyssynergy \\
3 & $40-59$ & $10-14$ & Systoles end phase II + contractions Continuous dyssynergy \\
& & & in all phases & \\
5 & $20-39$ & $<10$ & Few systoles in all phases & \\
5 & $<20$ & & Frequent systoles in all phases or & \\
& & & flaccid bladder &
\end{tabular}

${ }^{\mathrm{a}} \mathrm{CV}$ norm $=30+($ age in years $\times 30)$

detrusor contraction and complete relaxation occurring at the peak of this contraction (Chancellor type 1). Intermittent dyssynergy was characterized by sphincteric contractions arising intermittently and independently of the detrusor contractions (Chancellor type 2) and graded 2. A constant dyssynergy with a permanent crescendodecrescendo activity of the external sphincter along with detrusor activity (Chancellor type 3 ) was graded 3 .

Once graded, these four parameters were added to obtain a UDS score, which ranged from 0 to 17 . Patients were reassessed 6 months after surgery and then every 6 to 12 months depending on their clinical evaluation and on the UDS evolution, which were systematically performed in each child.

Control group

The control group included 38 patients ( 12 boys and 26 girls) aged 0 to 8 years (mean \pm SD: $3 \pm 3$ years), who were evaluated with UDS during the same period of time for primary or secondary enuresis and preoperative work-up for anorectal malformations. Patients with abnormal clinical micturition profiles, spinal cord lesions, dysraphic conditions, urinary tract malformations or infections, and abnormal VCUG, and patients receiving medications were excluded from the control group. All patients with an anorectal malformation had MRI in order to rule out a dysraphic condition.

Statistical analysis

The four parameters used for UDS evaluation and the total score should be considered as quantitative variables and parametric statistics were performed with the Statistical Package for Social Sciences (SPSS 10.0 for Windows). Means of grades for the four parameters and the UDS score between the control and study groups were compared using analysis of variance (ANOVA). The evolution before and after surgery was evaluated using $t$-paired samples.

\section{Results}

Preoperative clinical and radiological examinations

Thirteen out of 15 patients had skin marks (subcutaneous lipoma, hypertrichosis, angioma, or dermal sinus). In 5 patients, cutaneous stigmata were the only clinical manifestation of TCS. Neuromusculoskeletal syndrome (NMSS; acute paraplegia, foot deformity, limp, sensory loss, abolished deep tendon reflex) was present in 8 patients. Five patients had clinically evident bladdersphincteric disturbances. The remaining 10 patients had no observable sphincteric dysfunction. It has to be stressed that this clinical parameter was not reliable in 6 out of these 10 patients, who were less than 1 year of age at the time of diagnosis. Plain lumbar spine X-rays displayed a spinal dysraphism in 12 patients. Spinal MRI showed a low-situated conus medullaris secondary to lipomyelomeningocele in 9 patients, diastematomyelia in 3 , lipomatous filum in 2 , and a teratoma in 1 . VCUG demonstrated a vesico-ureteric reflux in 3 patients.

\section{Urodynamic studies}

In the control group, the mean UDS score \pm SE was $3.5 \pm 2.1$ (range 0 to 8 ). In the study group, the mean preoperative UDS score of $8.9 \pm 4.7$ (range 1 to 17) was statistically significantly higher $(p<0.001)$ than in the control group (Fig. 1). Of note, 8 out of the 10 patients without urinary symptoms had clearly abnormal scores. The 5 patients with obvious clinical bladder-sphincteric dysfunction had abnormal UDS scores. When each parameter was analyzed separately, means of grades of volume, compliance, detrusor activity, and vesico-sphincteric synergy were all statistically significantly higher in the study group than in the control group (Table 2).

The follow-up period ranged from 5 to 11 years (mean $84 \pm 24$ months). None of the 7 patients without preoperative NMSS deteriorated following surgery. Among the 8 patients with a preoperative NMSS, 1 recovered completely postoperatively. He presented with an acute paraplegia secondary to an infected dermal sinus. The remaining 7 patients were clinically unchanged postoperatively. Of the 10 patients without clinically relevant urinary symptoms, 7 remained asymptomatic, and 3 had clinically apparent bladder-sphincteric disturbances postoperatively. It should be noted that these 3 patients were less than 1 year of age at the time of surgery, and thus difficult to assess clinically. The UDS scores of these 3 patients were abnormal preoperatively. One of them 
Fig. 1 Urodynamic study (UDS) scores. Comparisons between the control group and the study group preoperatively, and between the study group preoperatively and 60 months postoperatively, with the 12 and 36 months postoperative evolution

Fig. 2 Postoperative evolution of UDS parameters and score in a patient with secondary retethering, 2 years after initial spinal cord untethering

Table 2 Comparison between control group and preoperative study group of isolated parameters and total UDS score
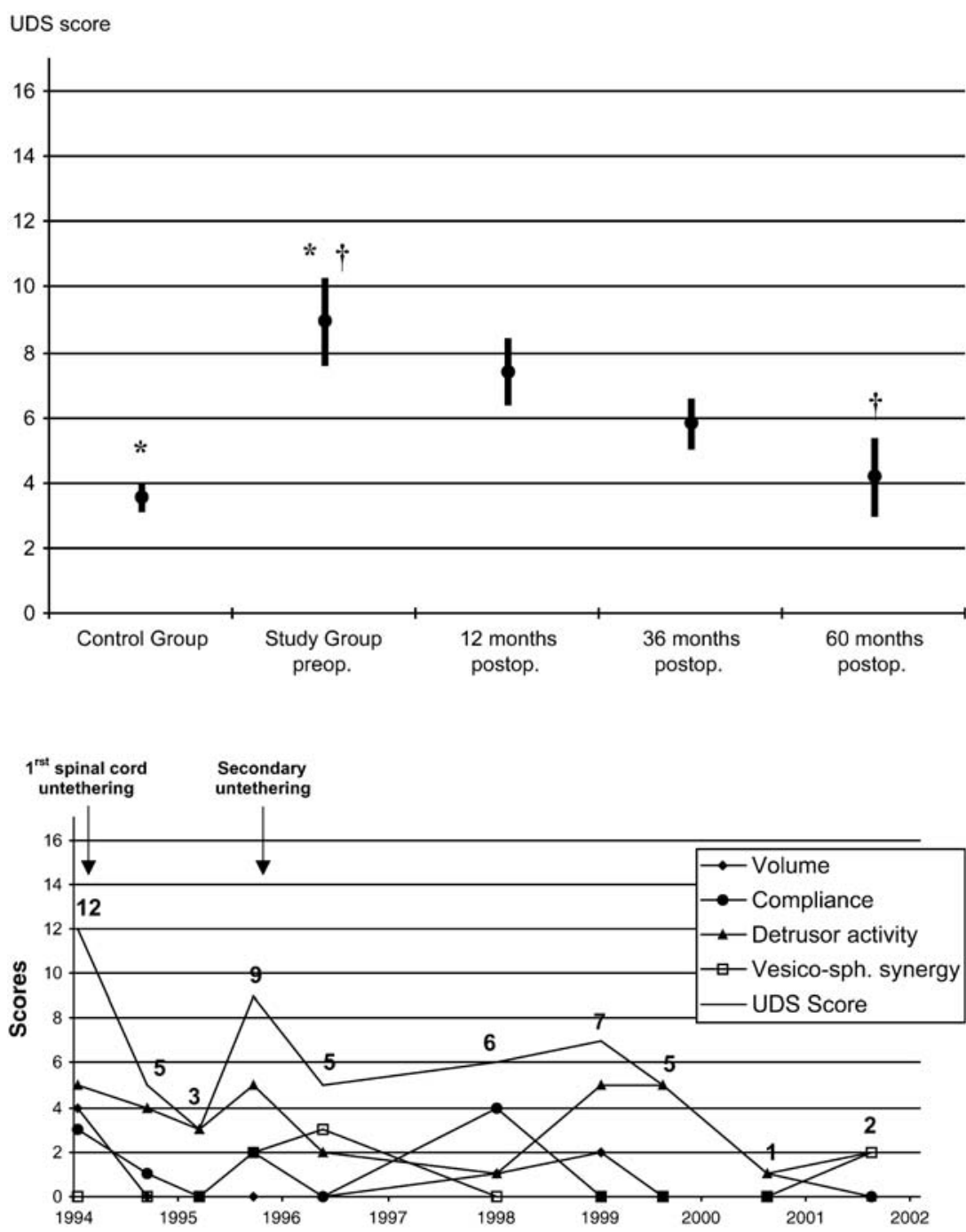

\begin{tabular}{lllrr}
\hline Parameter & $\begin{array}{l}\text { Control group } \\
n=38\end{array}$ & $\begin{array}{l}\text { Study group } \\
n=15\end{array}$ & \multicolumn{2}{l}{ Statistics } \\
\cline { 3 - 5 } & & & $F(1,51)$ & $p$ value \\
\hline Volume & $0.58(0.16)$ & $1.67(0.42)$ & 8.94 & 0.004 \\
Compliance & $1.24(0.24)$ & $2.33(0.44)$ & 5.40 & 0.024 \\
Detrusor activity & $0.79(0.19)$ & $3.20(0.58)$ & 26.40 & $<0.001$ \\
Vesico-sphincteric synergy & $0.92(0.16)$ & $1.73(0.32)$ & 6.50 & 0.014 \\
UDS score & $3.53(0.34)$ & $8.93(1.22)$ & 33.36 & $<0.001$ \\
\hline
\end{tabular}

Values represent means with standard errors: ANOVA with $F$ and $p$ values showed progressive deterioration of his UDS score 2 years after spinal cord untethering, with clinically evident micturition dysfunction. He benefited from a second spinal cord untethering. This was followed by an improvement in both his clinical condition and UDS score (Fig. 2). Overall, UDS scores showed a progressive improvement with a statistically significant difference 60 months after surgery (Fig. 1).

\section{Discussion}

This series reviews 15 children with closed spinal dysraphism, a term that seems more appropriate than occult dysraphism, considering the high percentage of cutaneous marks, which should raise the suspicion of an underlying dysraphic condition. In fact, $87 \%$ of our patients had such stigmata. A similar incidence rate was 
reported previously [1]. Accordingly, like others, we strongly believe that any midline cutaneous abnormality overlying the lower spine mandates a spinal MRI [1]. Neuro-orthopedic deficits are rare in closed spinal dysraphism during infancy or early childhood $[6,16$, $22]$. In our study, such deficits were encountered in $47 \%$ of patients, and not surprisingly, in patients with severe forms of diastematomyelia and lipomyelomeningocele.

Up to $67 \%$ of our patients had no obvious bladdersphincteric dysfunction preoperatively, which is in agreement with the literature $[9,16,17,22]$. This high percentage of urologically asymptomatic children illustrates the extreme difficulty of documenting neurourological disorders in infants and young children. In contrast, $87 \%$ of our patients $(n=14)$ had urodynamic abnormalities at initial examination. Moreover, $80 \%$ of urologically asymptomatic children had abnormal preoperative UDS. This high incidence rate is certainly not artifactual, since it was highly statistically different when compared with that of an age-matched control group. These findings stress the importance of the early detection of urodynamic dysfunction, since $92 \%$ of children with closed spinal dysraphism were reported, if not treated, to develop progressive neuro-urological disorders by the age of 3 years [16, 18, 29]. Although the importance of UDS in the evaluation of children with TCS has been well established $[15,21,26]$, the lack of objective and reproducible criteria of assessment often precludes their practical use in comparative studies. We thus aimed at proposing a reliable method of UDS analysis, in order to detect early neurological disorders in TCS patients preand postoperatively.

Previous attempts have been made to quantify urodynamic findings. These studies focused on isolated UDS parameters, such as bladder compliance [7, 13], bladdersphincteric dyssynergy, or bladder volume $[1,12]$. We used the same three parameters and added the analysis of detrusor activity during the filling phase as it reflects lesions of the upper motor neuron or of the ponto-sacral pathways. In order to allow an easy and reproducible means of assessment, these four parameters were first separately graded.

We compared the grade of each parameter in the study group with the ones in the control group, and found that each parameter appeared to be useful in assessing neurological disorders in TCS patients. Nevertheless, assuming they are studied separately, isolated parameters might not, in certain circumstances, reveal the preoper- ative neurological disorders or postoperative deterioration of patients. For instance, bladder volume often remains constant in patients with a flaccid bladder; contractions or systoles may be inhibited by medications such as oxybutinin, and a fixed bladder-sphincteric dyssynergy, secondary to complete lesion of the lower motor lesion, may remain unchanged postoperatively. For these reasons, individual grades were then added, giving the UDS score, which ranged from 0 to 17 . This method offers the advantage of detecting any UDS change as a whole.

In our practice, we now consider a UDS score ranging from 0 to 4 to be normal. A UDS score of 5 or 6 should raise the question of an underlying urological disorder, and certainly mandates repeated UDS. We regard a UDS score above 6 as abnormal. Chronological evolution of the UDS score in a patient is undoubtedly more important than an isolated result that could be influenced by external factors (i.e., discomfort, agitation, psychological stress). This emphasizes the need for repeating UDS when scores are abnormal or ambiguous. We now consider that degradation of the total UDS score of more than 2 points in two consecutive UDS reflects a neuro-urological aggravation. In operated TCS patients, it should raise the suspicion of spinal cord retethering, especially if there was an initial improvement in the UDS score following surgery.

Although conducted on a limited number of patients, this study demonstrated that children with primary tethered cord had a statistically significantly higher UDS score than those in an age-matched control group. Moreover, there was a statistically significant improvement in the postoperative UDS score during the long-term follow-up in the majority of these patients.

\section{Conclusions}

Urodynamic studies are more sensitive than clinical evaluation at detecting early neuro-urological abnormality or deterioration in children with primary or secondary TCS. The UDS score described in this study provides a sensitive and reliable tool for the early identification and quantification of neuro-urological disorders in children with primary tethered cord. It offers a simple and reproducible method of evaluating patients with a dysraphic condition both pre- and postoperatively. 


\section{References}

1. Bauer SB (1992) Neuropathy of the lower urinary tract. In: Kelalis PP, King LR, Belman AB (eds) Clinical pediatric urology. Saunders, Philadelphia, pp 399-440

2. Brading AF, Turner WH (1994) The unstable bladder: towards a common mechanism. Br J Urol 73:3-8

3. Chancellor MB, Kaplan SA, Blaivas JG (1990) Detrusor-external sphincter dyssynergia. Ciba Found Symp 151:195213

4. Colak A, Pollack IF, Albright AL (1998) Recurrent tethering: a common long-term problem after lipomyelomeningocele repair. Pediatr Neurosurg 29:184-190

5. DiPietro MA, Venes JL (1988) Realtime sonography of the pediatric spinal cord: horizons and limits. Concepts in pediatric neurosurgery, vol 8. Karger, Basel, pp 120-132

6. Foster LS, Kogan BA, Cogen PH, Edwards MS (1990) Bladder function in patients with lipomyelomeningocele. J Urol 143:984-986

7. Galloway NT, Mekras JA, Helms M, Webster GD (1991) An objective score to predict upper tract deterioration in myelodysplasia. J Urol 145:535-537

8. Garceau GJ (1953) The filum terminale syndrome (the cord traction syndrome). J Bone Joint Surg Am 35:711-716

9. Gross AJ, Michael T, Godeman F, Weigel K, Huland H (1993) Urological findings in patients with neurosurgically treated tethered spinal cord. J Urol 149:1510-1511

10. Hellstrom WJG, Edwards MSB, Kogan BA (1986) Urological aspects of the tethered cord syndrome. J Urol 135:317-320

11. Hjalmas K (1988) Urodynamics in normal infants and children. Scand J Urol Nephrol 114 [Suppl]:20-27
12. Houle AM, Gilmour RF, Churchill BM, Gaumond M, Bissonnette B (1993) What volume can a child normally store in the bladder at a safe pressure? J Urol 149:561-564

13. Houser EE, Bartholomew TH, Cookson MS, Marlin AE, Little NA (1994) A prospective evaluation of leak point pressure, bladder compliance and clinical status in myelodysplasia patients with tethered spinal cords. J Urol 51:177-181

14. Johnson DL, Levy LM (1995) Predicting outcome in the tethered cord syndrome: a study of cord motion. Pediatr Neurosurg 22:115-119

15. Kaplan SA, Chancellor MB, Blaivas JG (1991) Bladder and sphincter behaviour in patients with spinal cord lesions. $\mathbf{J}$ Urol 146:113-117

16. Keating MA, Rink RC, Bauer SB, Karup C, Dyro FM, Winston KR, Shillito J, Fischer EG, Retik AB (1988) Neurourological implications of the changing approach in management of occult spinal lesions. J Urol 140:12991301

17. Khoury AE, Hendrick EB, McLorie GA, Kulkarni A, Churchill BM (1990) Occult spinal dysraphism: clinical and urodynamic outcome after division of the filum terminale. J Urol 144:426-429

18. Kondo A, Kato K, Kanai S, Sakakibara T (1986) Bladder dysfunction secondary to tethered cord syndrome in adults: is it curable? J Urol 135:313-316

19. Norgaard JP, Van Gool JD, Hjalmas, Djurhuus JC, Hellstrom AL (1998) Standardization and definitions in lower urinary tract dysfunction in children. $\mathrm{Br}$ J Urol 81 [Suppl 3]:1-16

20. O’Neill P, Stack JP (1990-1991) Magnetic resonance imaging in the preoperative assessment of closed spinal dysraphism in children. Pediatr Neurosurg 16:240-246
21. Palmer LS, Richards I, Kaplan WE (1998) Subclinical changes in bladder function in children presenting with non urological symptoms of the tethered cord syndrome. J Urol 159:231-234

22. Pierre-Kahn A, Zerah M, Renier D, Cinalli G, Sainte-Rose C, LellouchTubiana A, Brunelle F, Le Merrer M, Giudicelli Y, Pichon J, Kleinknecht B, Nataf F (1997) Congenital lumbosacral lipomas. Childs Nerv Syst 13:298-334

23. Roy MW, Gilmore R, Walsh JW (1986) Evaluation of children and young adults with tethered spinal cord syndrome. Utility of spinal and scalp recorded somatosensory evoked potentials. Surg Neurol 26:241-248

24. Tani S, Yamada S, Knighton RS (1987) Extensibility of the lumbar and sacral cord. Pathophysiology of the tethered spinal cord in cats. J Neurosurg 66:116123

25. Van Gool JD, Dick P, de Jong TP (2001) Bladder-sphincter dysfunction in myelomeningocele. Eur J Pediatr 160:414-420

26. Vernet O, Farmer JP, Houle AM, Montes JL (1996) Impact of urodynamic studies on the surgical management of spinal cord tethering. J Neurosurg 85:555-559

27. Vernet O, O'Gorman AM, Farmer JP, McPhillips M, Montes JM (1996) Use of the prone position in the MRI evaluation of spinal cord retethering. Pediatr Neurosurg 25:286-294

28. Yamada S, Zinke DE, Sanders D (1981) Pathophysiology of "tethered cord syndrome". J Neurosurg 54:494-503

29. Yip CM, Leach GE, Rosenfeld DS, Zimmen P, Raz S (1985) Delayed diagnosis of voiding dysfunction: occult spinal dysraphism. J Urol 134:694-697 